\title{
Peripheral Arterial Embolism. Report of Hospitalized Cases
}

\author{
Antonio Carlos Pereira Barretto, Moacyr Roberto Cuce Nobre, Alfredo José Mansur, Aírton Scipioni, \\ José Antonio Franchini Ramires
}

São Paulo, SP - Brazil

\begin{abstract}
Objective - We analyzed the frequency of peripheral embolisms, the underlying heart disease, triggering factors, the sites of the emboli, and evolution of the patients.

Methods - We analyzed 29 cases of peripheral arterial embolism out of a total of 20,211 hospitalizations in a cardiology center in the city of São Paulo. The age was $51.89 \pm 18.66$ years, and 15 were males.
\end{abstract}

Results - Embolism in the right lower limb occurred in 18 patients $(62.0 \%)$, in the left lower $11(37.9 \%)$ and right upper $3(10.3 \%)$ limbs, and in the left arm (1). Four patients had embolism in two limbs. The heart disease, mitral valvar heart disease (9 patients-31.0\%); infective endocarditis (7-24.1\%); dilated cardiomyopathy (6 $20.6 \%$ ); ischemic coronary heart disease (6 patients $20.6 \%)$; and one patient with cor pulmonale. Atrial fibrillation was observed in 20 patients (68.9\%), chronic in 12 patients $(41.3 \%)$ and acute in $8(27.5 \%)$. All patients with mitral valvar heart disease had atrial fibrillation, chronic in 8 patients (88.8\%); patients with cardiomyopathy and coronary heart disease, 4 in each group had atrial fibrillation, acute in $60 \%$ of the patients.Patients with infective endocarditis, 3 had staphylococcus and 2 Gram-negative bacteria. In the follow-up, 2 patients (6.8\%) required limbs amputation, and $5(17.2 \%)$ died due to embolism.

Conclusion - Most of the time, embolism does not cause permanent complications. Our data highlight the importance of anticoagulation for patients acute atrial fibrillation in myocardial dysfunction and for patients with chronic atrial fibrillation in cases of mitral valvar heart disease to prevent peripheral embolism.

Key words: heart failure, valvar heart disease, peripheral arterial embolism, atrial fibrillation.

Instituto do Coração do Hospital das Clínicas - FMUSP

Mailing Address: Antonio Carlos Pereira Barretto - Incor - Serviço de Prevenção e Reabilitação - Av. Dr. Enéas C. Aguiar, 44 - 05403-000 - São Paulo, SP, Brazil
The heart is the most common source of emboli ${ }^{1-3}$. Some heart diseases, such as mitral valvar heart disease ${ }^{4,5}$, metallic or biological valvar prostheses with dysfunction ${ }^{4,5}$, myocardial infarction with akinetic areas ${ }^{6}$, atrial fibrillation ${ }^{7,8}$, infective endocarditis ${ }^{1,2}$, and heart failure ${ }^{9-14}$ among others are known to predispose patients to thromboembolic phenomena. The frequency with which these thromboembolic phenomena occur varies with the underlying heart disease.

In hospitals specializing in cardiology, the potential occurrence of embolisms creates the demand for specialized medical support for acute episodes and long-term therapeutical orientation in the chronic phase with implications in prevention. Mainly in patients with heart disease, data provided by the echocardiogram may be useful ${ }^{14}$.

We studied the frequency of peripheral thromboembolic phenomena in a tertiary hospital in São Paulo specializing in cardiology, during 2 consecutive years. We tried to identify the main characteristics of the phenomena, their morbidity, possible triggering factors, and we discussed measures for prevention.

\section{Methods}

We analyzed data from patients admitted to INCOR in the years of 1996 and 1997, which were obtained from the PRODESP database and originated from admission, discharge, and death reports provided by the department of medical records and statistics.

The following parameters were analyzed: a) site of embolism; b) characteristics of the heart disease; c) duration of the disease; d) echocardiographic data; e) use of anticoagulants; f) presence of atrial fibrillation; g) complications due to the embolic process; h) surgeries and deaths occurring during hospitalization.

Embolism to cerebral arteries was not studied because of the difficulty in differentiating that process from atherosclerotic ischemic stroke in a retrospective analysis, mainly considering the elderly patients admitted to our hospital.

Echocardiographic data were obtained in 24 cases. The following parameters were assessed: left ventricular diastolic diameter, ejection fraction, left atrial diameter, and the presence of an image suggesting cavitary thrombus or vegetation. 
The frequency of the several diagnoses and the values of mean and standard deviation of the analyzed variables are shown.

\section{Results}

In the period of time studied, out of a total of 20,211 admissions to the hospital, 29 patients had peripheral arterial embolism. Fifteen were men and 14 were women, with ages ranging from 10 to 86 years (mean of $51.9 \pm 18.7$ years).

These 29 patients had 40 embolic episodes. Thirtythree episodes occurred in the upper and lower limbs, one in the mesenteric artery, and one in the kidney. The embolism episodes occurred as follows: 18 in the right lower limb, 11 in the left lower limb, 3 in the right upper limb, and one in the left upper limb. Six patients had embolisms in more than one location as follows: 3 patients had simultaneous embolisms in both lower limbs, one patient had embolisms in the left lower and right upper limbs, another patient in the right lower limb and kidney, and another patient in the right lower limb and mesenteric artery. Five patients also had probable embolic strokes.

The underlying heart diseases (fig. 1) were distributed as follows: mitral valvar heart disease in 9 cases; bacterial endocarditis in 7 cases; cardiomyopathy in 6 cases; dilated cardiomyopathy in 5 cases; hypertrophic cardiomyopathy in one case; coronary artery disease in 6 cases; and heart disease secondary to pulmonary hypertension in one case.

All patients with valvar heart disease as the main diagnosis had impairment of the mitral valve. Four patients had undergone prior replacement of the mitral valve for a biological prosthesis; one patient had undergone valvoplasty; and four patients had a stenotic valve, 2 of whom also had simultaneous aortic valve lesion.

All patients with infective endocarditis (main diagnosis) had valvar heart disease as follows: 4 had impairment of the mitral valve and 3 patients had impairment of the aortic valve. In 5 of these patients, the infective agent could be

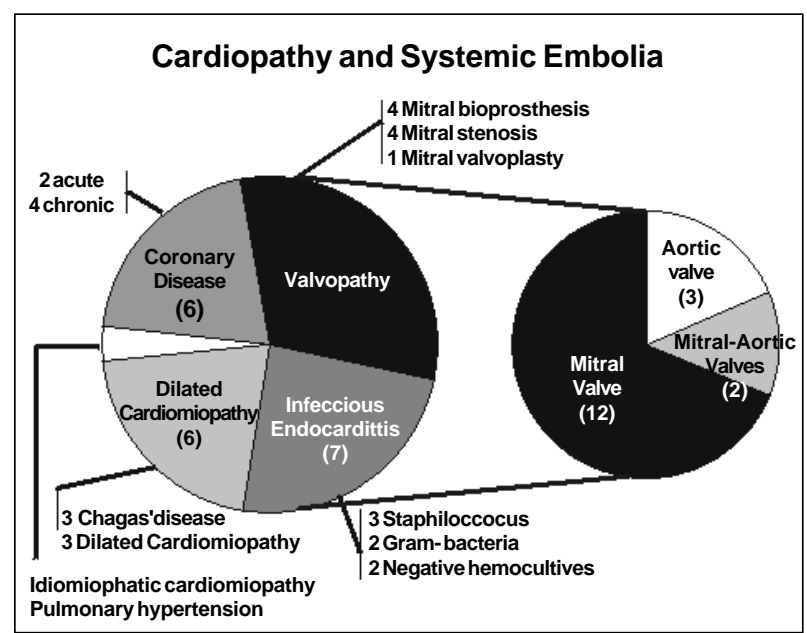

Fig. 1 - Graphic showing the incidence of underlying heart disease. in those cases with heart valvar impairment, the impaired valve was identified. identified: it was the staphylococcus in 3 patients and Gramnegative bacteria in 2 patients. In the 2 remaining patients, blood cultures were negative.

In regard to the patients with coronary artery disease, 2 were in the acute phase of myocardial infarction and 4 had chronic ischemic disease.

The duration of the heart disease preceding the embolic phenomenon varied from a few days to 23 years (mean of 8 years and 3 months).

Echocardiographic data are shown in table I.

The echocardiogram allowed the identification of cavitary thrombi in 3 cases ( 2 in the left ventricle and 2 in the left atrium - one of the cases had thrombi in 2 chambers). All cases had atrial fibrillation. The suggestive image of vegetation in the valve was detected in 5 cases of infective endocarditis.

The patients with atrial fibrillation showed in the echocardiogram a mean left atrial diameter of $47.66 \pm 7.94 \mathrm{~mm}$, and those patients without atrial fibrillation had a mean left atrial diameter of $43.16 \pm 10.04 \mathrm{~mm}$.

The patients with dilated cardiomyopathy had a mean left ventricular diameter of $63.60 \pm 8.50 \mathrm{~mm}$, a mean left atrial diameter of $45.60 \pm 4.15 \mathrm{~mm}$, and an ejection fraction of $0.43 \pm 0.13 \mathrm{~mm}$.

None of the 29 patients had used anticoagulants prior to the embolic event. After the embolic episodes, 19 patients were prescribed oral anticoagulants.

Atrial fibrillation (fig. 2) was identified in 20 cases, being chronic in 12 and acute in 8 . Chronic atrial fibrillation was observed in 8 patients with valvar heart disease, in 2 patients with bacterial endocarditis, in the patient with hypertrophic cardiomyopathy, and in one patient with coronary artery disease. Acute atrial fibrillation occurred in 3 patients with coronary heart disease; in 3 patients with cardiomyopathy, 2 of whom had dilated cardiomyopathy and one with Chagas' heart disease; in one patient with mitral valvar heart disease, and in the patient with pulmonary hypertension.

Fourteen patients underwent embolectomy performed with a Fogarty embolectomy catheter.

Two patients evolved with ischemia of the lower limbs resulting in amputation of the left lower limb in one patient and in amputation of both lower limbs at the level of the thigh in another patient.

In the follow-up until 1998, 12 patients died; 5 may have died due to complications from systemic embolism that contributed to clinical deterioration of the patients.

\section{Discussion}

The pathophysiology of embolism varies according to the heart disease. Embolism results from the release of fragments of a vegetation in infective endocarditis, the release of a mural thrombus in patients with myocardial infarction, the release of atrial thrombi in patients with mitral stenosis or prosthetic dysfunction, or the release of thrombi of an apical aneurysm in patients with Chagas' heart disease.

Our results lead us to the suggestion that peripheral 


\begin{tabular}{|c|c|c|c|c|c|c|c|c|c|c|}
\hline \multirow[b]{2}{*}{ Id } & \multirow[b]{2}{*}{ Sex } & \multirow[b]{2}{*}{ Age } & \multirow[b]{2}{*}{ LV } & \multicolumn{2}{|c|}{ Echocardiogram } & \multirow[b]{2}{*}{ Thrombus } & \multirow[b]{2}{*}{$\mathrm{AF}$} & \multirow[b]{2}{*}{ Acute } & \multirow[b]{2}{*}{ Site of embolism } & \multirow[b]{2}{*}{ Main heart Disease } \\
\hline & & & & $\mathrm{EF}$ & LA & & & & & \\
\hline 1 & $\mathrm{~F}$ & 72 & 43 & 72 & 35 & $\mathrm{~N}$ & $\mathrm{~S}$ & $\mathrm{~N}$ & RIL & Main heart Disease \\
\hline 2 & $\mathrm{~F}$ & 44 & 44 & 67 & 48 & $\mathrm{~S}$ & $\mathrm{~S}$ & $\mathrm{~S}$ & RIL & Mitral valvar disease \\
\hline 3 & M & 65 & & 55 & & $\mathrm{~S}$ & $\mathrm{~S}$ & $\mathrm{~S}$ & RSL & Mitral valvar disease \\
\hline 4 & M & 59 & 55 & 71 & 51 & VEG & $\mathrm{S}$ & $\mathrm{N}$ & RIL & Acute coronary heart disease \\
\hline 5 & M & 70 & 62 & 74 & 46 & $\mathrm{~N}$ & $\mathrm{~N}$ & $\mathrm{~N}$ & RIL & Mitral valvar disease + endocarditis \\
\hline 6 & $\mathrm{~F}$ & 15 & & & & VEG & $\mathrm{S}$ & $\mathrm{N}$ & RSL + LIL & Mitral/Aortic valvar disease \\
\hline 7 & $\mathrm{~F}$ & 50 & 45 & 73 & 58 & $\mathrm{~N}$ & $\mathrm{~S}$ & $\mathrm{~N}$ & LIL & Mitral valvar disease + endocarditis \\
\hline 8 & M & 65 & & & & $\mathrm{~N}$ & $\mathrm{~S}$ & $\mathrm{~S}$ & LIL & Mitral valvar disease \\
\hline 9 & $\mathrm{~F}$ & 31 & 82 & 29 & 57 & $\mathrm{~N}$ & $\mathrm{~S}$ & $\mathrm{~S}$ & $\mathrm{RSL}+\mathrm{LIL}$ & Chronic coronary heart disease \\
\hline 10 & $\mathrm{M}$ & 10 & 44 & 68 & 27 & VEG & $\mathrm{N}$ & $\mathrm{N}$ & MIE & Mitral valvar disease + endocarditis \\
\hline 11 & M & 53 & 57 & 78 & 57 & VEG & $\mathrm{S}$ & $\mathrm{N}$ & MIE & Aortic valvar disease + endocarditis \\
\hline 12 & $\mathrm{~F}$ & 55 & 54 & 38 & 40 & $\mathrm{~N}$ & S & $\mathrm{S}$ & MID & Aortic valvar disease + endocarditis \\
\hline 13 & $\mathrm{M}$ & 44 & 70 & 27 & 43 & $\mathrm{~N}$ & $\mathrm{~S}$ & $\mathrm{~N}$ & MID + IE & Idiopathic dilated cardiomyopathy \\
\hline 14 & M & 29 & 46 & 75 & 39 & $\mathrm{~N}$ & $\mathrm{~N}$ & $\mathrm{~N}$ & MID & Chagas' heart disease \\
\hline 15 & M & 48 & 66 & 78 & 44 & VEG & $\mathrm{N}$ & $\mathrm{N}$ & MIE & Aortic valvar disease + endocarditis \\
\hline 16 & M & 68 & 48 & 68 & 38 & $\mathrm{~N}$ & $\mathrm{~S}$ & $\mathrm{~N}$ & MSD & Aortic valvar disease + endocarditis \\
\hline 17 & M & 53 & 71 & 39 & 57 & $\mathrm{~N}$ & $\mathrm{~S}$ & $\mathrm{~N}$ & MID & Mitral valvar disease \\
\hline 18 & $\mathrm{~F}$ & 75 & 55 & 48 & 49 & $\mathrm{~N}$ & $\mathrm{~N}$ & $\mathrm{~N}$ & MID & Mitral/Aortic valvar disease \\
\hline 19 & $\mathrm{~F}$ & 56 & 48 & 70 & 43 & $\mathrm{~N}$ & $\mathrm{~N}$ & $\mathrm{~N}$ & MID + mesexteric & Chagas' heart disease \\
\hline 20 & $\mathrm{~F}$ & 59 & & 17 & & $\mathrm{~N}$ & $\mathrm{~N}$ & $\mathrm{~N}$ & MIE & Mitral valvar disease \\
\hline 21 & $\mathrm{~F}$ & 43 & & & & $\mathrm{~N}$ & $\mathrm{~S}$ & $\mathrm{~N}$ & MID + Renal & Acute coronary heart disease \\
\hline 22 & $\mathrm{~F}$ & 75 & 50 & 65 & & $\mathrm{~S}$ & $\mathrm{~S}$ & $\mathrm{~S}$ & MID & Mitral valvar disease \\
\hline 23 & M & 46 & 53 & 77 & 60 & $\mathrm{~N}$ & $\mathrm{~S}$ & $\mathrm{~S}$ & MID & Chronic coronary heart disease \\
\hline 24 & M & 46 & 67 & 63 & 46 & $\mathrm{~N}$ & $\mathrm{~S}$ & $\mathrm{~N}$ & MID & Hypertrophic cardiomyopathy \\
\hline 25 & $\mathrm{~F}$ & 22 & 47 & 68 & 48 & $\mathrm{~N}$ & S & $\mathrm{S}$ & MID & Idiopathic dilated cardiomyopathy \\
\hline 26 & $\mathrm{~F}$ & 70 & & & & $\mathrm{~N}$ & $\mathrm{~N}$ & $\mathrm{~N}$ & MID & Mitral valvar disease \\
\hline 27 & $\mathrm{~F}$ & 74 & & & & & $\mathrm{~S}$ & $\mathrm{~N}$ & MID + IE & Chronic coronary heart disease \\
\hline 28 & M & 86 & 48 & 76 & 38 & $\mathrm{~N}$ & $\mathrm{~N}$ & $\mathrm{~N}$ & MIE & Pulmonary hypertension \\
\hline 29 & $\mathrm{M}$ & 55 & 72 & 39 & 50 & $\mathrm{~N}$ & $\mathrm{~S}$ & $\mathrm{~N}$ & MSD & Chagas' heart disease \\
\hline
\end{tabular}

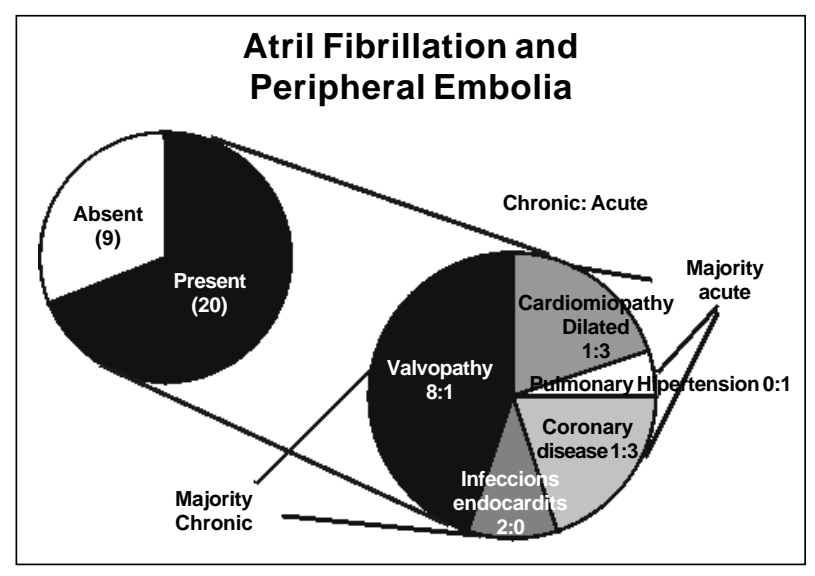

Fig. 2 - Graphic highlighting the presence of atrial fibrillation, its relation with the underlying heart disease, and indication of the cases of cases of acute and chronic fibrillation.

thromboembolic phenomena are not common events or that they do not cause sequelae that require hospitalization for control. This is based on the observation that out of more than 20 thousand hospitalizations at INCOR in 2 consecutive years, we identified only 29 patients with peripheral embolisms. Thromboembolic phenomena are obviously much more common than we detected. This may be due to the fact that we did not consider the embolic events to the cerebral region, we identified only a small number of cases with embolism to the viscera, and we did not consider the hospitali- zations due to peripheral embolisms occurring in the vascular surgery unit or in other services of the hospital complex.

These results, however, are not very different from those published in the literature, where only a small number of thromboembolic phenomena are described, and cerebral strokes are stressed to be 4 to 20 times more common than the peripheral arterial ones ${ }^{1-3,6,7}$. Results of postmortem examinations have shown that the incidence of embolic phenomena is higher than that diagnosed antemortem, and that the kidneys are the most common sites of embolism, passing usually unnoticed ${ }^{9}$.

As already mentioned in this study, embolisms to cerebral arteries were not analyzed because of the difficulty in a retrospective approach to differentiating them from ischemic stroke, especially considering the elderly population that seeks our hospital.

In one study performed in patients with Chagas' heart disease ${ }^{9}$, the site of embolism was assessed on postmortem examination. In 101 autopsies, 26 cases of systemic embolism were identified, of which, 21 involved the kidneys, 4 the splenic artery, 2 the cerebral and iliac arteries, and one the mesenteric artery. These results show that embolism to the limbs were less common than to the abdominal organs. The embolism was not diagnosed ante-mortem in most of these cases, probably because the symptoms were similar to those resulting from splanchnic congestion. It is worth noting that in this series cerebral embolism was not common, unlike reports in the literature. 
Data from the study conducted at INCOR allow us to infer which heart diseases are more prone to embolization and speculate about the ways of prevention and treatment.

Considering that endocarditis is not common in the population, its high incidence (24.1\%) in our series suggests a high potential to originate emboli in endocarditis caused by staphylococci and Gram-negative bacteria. Considering still the prevalence of patients with coronary heart disease and dilated cardiomyopathy and even mitral valvar heart disease, figures found in this series may be considered small as compared with the amount of cases in the population. This may allow us to think that embolic phenomena in these diseases are rare or the prophylactic anticoagulant measures adopted are being effective.

In the cases of infective endocarditis, the studies suggested a correlation between the size of the vegetation and the presence of embolism, showing that embolisms are more frequent in patients with vegetations larger than $10 \mathrm{~mm}^{2,3}$. As already largely demonstrated, infections caused by staphylococci or Gram-negative bacteria, considered highly virulent, cause embolism more frequently. In our cases, these bacteria were identified in $62.5 \%$ of the patients. In those cases where the agent was not identified, that etiologic possibility could not be completely excluded.

Evidence exists indicating that in the cases of infective endocarditis caused by staphylococci or Gram-negative bacteria, the embolic phenomena occur in the initial phase of the disease as in our observation. In endocarditis caused by streptococci of the viridans group even though rarer, these phenomena tend to occur later ${ }^{1}$.

In the cases of mitral stenosis and prosthetic dysfunction, acute or chronic atrial fibrillation plays a significant role in the genesis of thromboembolism ${ }^{2,7,8}$. In the Framingham study, during 28 years of follow-up, the presence of rheumatic valvar heart disease and atrial fibrillation identified a group with an incidence of cerebral embolism 17 times higher. In the patients with isolated atrial fibrillation, this incidence was 5 times higher than in those patients without atrial fibrillation.

In cases of cardiomyopathy and myocardial infarction, the formation of thrombi in dyskinetic regions of the ventricles and the atria in the presence of atrial fibrillation is the origin of the emboli ${ }^{3,6-8}$.

In our patients with dilated cardiomyopathy and coronary heart disease, most of the embolizations occurred during an episode of acute atrial fibrillation, and most of those individuals with mitral valvar heart disease had chronic atrial fibrillation. These data suggest the importance of anticoagulation measures in atrial fibrillation. Most of those individuals with valvar heart disease, however, have the arrhythmia for a relatively long time allowing us to suppose that other phenomena, such as the degree of valvar lesion or the size of the left atrium may be determinants in the formation of the thrombus.

In cases of infective endocarditis, atrial fibrillation was not the triggering factor.

Data of our study allowed the observation that among patients with dilated cardiomyopathy, peripheral thromboembolic phenomena did not occur in individuals with a sig- nificant ventricular impairment, which is a condition where anticoagulation is usually proposed ${ }^{10-15}$. In this case series, the patients had a mean ejection fraction of 0.43 and left ventricular diameter of $63.80 \mathrm{~mm}$, which do not characterize a significant ventricular impairment. These data probably highlight the importance of acute or intermittent atrial fibrillation as a causal factor for thromboembolic phenomena and allow us to question the systematic anticoagulation of patients with ventricular dysfunction, even those with a significant ventricular impairment ${ }^{14,15}$. On the other hand, these data emphasize the importance of anticoagulation for those patients with acute atrial fibrillation, even though we have to consider that the embolic phenomenon sometimes is the first clinical manifestation of this arrhythmia.

In regard to the embolic sites, we could observe that the lower limbs were much more involved than the upper ones. The right iliac artery was the most impaired (11-37.9\%). We could not find an anatomical explanation for these findings; perhaps it is the direction of the blood flow through the aorta.

As already mentioned, other organs are more frequently involved than reported; however, due to the lack of specific clinical manifestation their impairment passes unnoticed in the majority of the patients. In our case series, one case of embolism to the mesenteric artery and another to the kidney were identified and may have been diagnosed because of the magnitude of the manifestation.

Five out of the 29 patients had cerebral embolism.

In the study based on the analysis of autopsies ${ }^{9}$, embolisms to the limbs were not common, comprising $3 \%$ of the systemic emboli identified in 101 patients. It would be interesting to assess the prognostic value of investigative tools in patients prone to embolization, in the presence of visceral manifestation, such as acute renal failure. With this management we would be able to identify, antemortem, the cases of renal embolism and orient the treatment and maybe even modify its course.

Most of the cases had clinical manifestations that indicated the need for an intervention of the embolectomy type, with most of the patients evolving practically with no sequelae after the procedure ( $83.8 \%$ ). In 2 cases these measures were not effective and amputation of the impaired limbs was required. In 5 cases (17.2\%) embolism caused alterations that impaired the clinical findings of the patients, who ended up dying because of these complications. It is worth noting that despite the severity of the situation, most of the patients rapidly treated had a good outcome.

These results lead to the conclusion that peripheral thromboembolic phenomena are not frequent findings. It is important to stress the significance of infective endocarditis as a cause of these embolic phenomena, of chronic atrial fibrillation in patients with lesions in the mitral heart valve or in the mitral prosthesis, and of acute atrial fibrillation in patients with ventricular dysfunction, either due to dilated or ischemic cardiomyopathy. These results could also lead to the supposition that anticoagulation might avoid accidents; however, the low incidence of embolisms in relatively common diseases challenges its therapeutical value, suggesting the need of clinical trials for confirmation. 


\section{References}

1. Karchmer AW. Infective Endocarditis. In: Braunwald E (ed). Heart Disease: A Text Book of Cardiovascular Medicine. $19^{\text {th }}$ edition. Philadelphia: WB Saunders Co., 1997: 1085 e 1095.

2. Braunwald E. Valvar Heart Disease. In: Braunwald E(ed). Heart Disease: A Text Book of Cardiovascular Medicine. $19^{\text {th }}$ edition. Philadelphia: WB Saunders Co., 1997: 1010.

3. Zieve PH, Waterbuy P. Thromboembolic disease. In: Barker LR, Burton JR, Zieve $\mathrm{PH}$ (eds). Principles of Ambulatory Medicine. $4^{\text {th }}$ edition. Baltimore: Willian \& Wilkson 1994: 621-4.

4. Fuster V, Stein B, Halperin JL, Chesebro JH. Antithrombotic therapy in cardiac disease: na approach based on pathogenesis and risk stratification. Am J Cardiol 1990; 65: 38C-44C

5. Saour JN, Sieck JO, Mamo LA, et al. Trial of different intensities of anticoagulation patients with prosthetic heart valves. N Engl J Med 1990; 322: 428-32.

6. The stroke prevention in atrial fibrillation investigators: Predictors of thromboembolism in atrial fibrillation, I: clinical features of patients at risk. Ann Intern Med 1992; 116: 1-5.

7. The stroke prevention in atrial fibrillation investigators: Predictors of thromboembolism in atrial fibrillation: final results. Circulation 1991; 84: 527-34.

8. Drapkin A, Merskey C. Anticoagulant therapy after acute myocardial infarction: relation of therapeutic benefit to patient's age, sex, and severity of infarction. JAMA 1972; 222: 541-8.

9. Arteaga-Fernandez E, Pereira-Barretto AC, Ianni BM, et al. Trombose cardíacae embolia em pacientes falecidos de cardiopatia chagásica crônica. Arq Bras Cardiol 1989; 52: 189-92.

10. Fuster V, Gersh BJ, Giuliani ER, et al. The natural history of idiopathic dilated cardiomyopathy. Am J Cardiol 1981; 47: 525-31

11. Roberts W, Siegel RJ, McManus BM. Idiopathic dilated cardiomyopathy: analysis of 152 necropsy patients. Am J Cardiol 1987; 60: 1340-55

12. Dunkman WB, Johnson GR, Carson PE, et al. Incidence of thromboembolic events in congestive heart failure. Circulation 1993; 87(suppl VI): 94-101.

13. Natterson PD, Stevenson WG, Saxon LA, et al. Risk of arterial embolization in 224 patients awaiting cardiac transplantation Am Heart J 1995; 129: $564-70$.

14. Dries DL, Rosenberg YD, Waclawiw MA, Domanski MJ. Ejection fraction and risk of thromboembolic events in patients with systolic dysfunction and sinus rhythm: Evidence for gender differences in the studies of left ventricular dysfunction trials. J Am Coll Cardiol 1997; 29: 1074-80.

15. Dunkman WB, Johnson GR, Carson PE, et al. Incidence of thromboembolic events in congestive heart failure. Circulation 1993; 87(suppl VI): 94-101. 